\title{
Application of Simple Dynamical System to Study the Hydrological Dynamics of a Mookervat Catchment Area
}

\author{
Agus Salim ${ }^{1,}$, Thamzil Las ${ }^{1}$, Nur Aida ${ }^{1}$, Silvan Erusani ${ }^{1}$, Albertus Sulaiman ${ }^{2}$ \\ ${ }^{1}$ Faculty of Science and Technology, Universitas Islam Negeri Syarif Hidayatullah, Indonesia \\ ${ }^{2}$ Geostech Laboratory BPPT,Kawasan Puspiptek Serpong, Indonesia.
}

\begin{abstract}
The paper study the characteristic of catchment behavior by using a simple first-order nonlinear dynamical system. The study area was located in a part of Jakarta Urban Lake was called Mookervart catchment area with some part of them are artifical river. The aims of the paper are to discover a new method to describe and to predict the dynamical of Mookervart river system by using a parameter simplify run off and rainfall. The average of rainfall was taken as long12 year showed that rainfall in Mookervart River under $500 \mathrm{~mm} / \mathrm{month}$ which called as a "wet month". Mookervart river system was caused by 2 season: wet and dry month. The dry month starting from month of May up to October and wet month from November to April. In 2010 the wet month more longest than other year is caused by La Nina effect. By using the $\alpha=3$ then the equation has two solution, this is mean that the solution is not unique. When the value of parameter increase then there are many kind of solution. This condition is called bifurcation. The rainfall on 8th days shown that increasing and decreasing from 15th day and then stabilize from 20th day to 100th day. Run off on the 18th days shown that increasing optimally and stabilize from 18th day to 100th day. The part or $50 \%$ of rainfall can be absorp to the land and others can be change to the runoff form. The application this model into the observation data of Mookervart catchment area is still developed. This is a restriction of a parameter value in our system that proofed that the behavior of the solution will be highlighted.
\end{abstract}

\section{Introduction}

Water fluxes in catchment area is very complicated phenomena which controlled by various physical processes and material properties. The recent advances technology such as satellite remote sensing, computer technology and geographic information system including digital terrain model an digital elevation model can be used to handle this complicated problem. The spatial problem canbe solved by these technology but the catchments dynamics is time depending and prediction the behavior in the future is still unresolved [1].

To describe time dependent of the complex phenomena, scientist use a physical parameter and investigate it by using a model. For example, the mayor theme in catchment

*Corresponding author: agus_salim@uinjkt.ac.id 
hydrology has been the interpretation of streamflow variations interms of the drainage behavior of hillslope or channel storage elements [2]. In this paper we propose a model that the complex catchment area can be studied by a simple model that is a nonlinear differential equation. This idea is proposed by Kirchner [3]. He showed that one class of catchment can be characterized as simple first-order nonlinear differential dynamical systems. This approach can be used to reconstructing precipitation and evapotranspiration where direct measurements are unavailable.

\section{Methodology}

\subsection{Field Site and Data}

The location of research was located in Mookervart Catchment area.The Mookervart catchment area is the region surrounding the Mookervart river. The part of the Mookervart river i.e. close to the mouth of estuary is artificial river. This river have the average $4.5 \mathrm{~m}$ depth and $32 \mathrm{~m}$ and $14 \mathrm{~m}$ width for the upper and the bottom respectively. The river can be storage of the discharge is about $125 \mathrm{~m}^{3} / \mathrm{s}$. The area surrounding the river was used as a urban, industry and factory. The Mookervart cacthment area $\left(67 \mathrm{~km}^{2}\right)$ is part of DKI Jaya province with the position is $106,38^{\prime}, 15^{\prime}$ " to $106,44^{\prime}, 50$ " E and $6,10^{\prime}, 20$ " to $6,09^{\prime}, 10^{\prime} \mathrm{N}$. The catchment have water input from the Cisadane river and the output in West DKI beach. The tropical climate is dominant in this catchment area and have high rainfall. The topography of this catchment is relatively flat with the rank $0-25 \mathrm{~m}$. The cathment area is depicted in Fig.1.

Mookevart river was initially used to be a river transportation and irrigation facility. In 1981 Mookervart river was designated to accommodate the discharge water capacity of $125 \mathrm{~m}^{3} / \mathrm{s}$, with the following dimensions: wide cross-section over the river $32 \mathrm{~m}$, a depth of $4.5 \mathrm{~m}$ and a base width of the river cross-section is $14 \mathrm{~m}$. The current conditions of the Mookervart river right now has wide cross-section span over the river varies between $10 \mathrm{~m}-33 \mathrm{~m}$ with a depth of cross-section between $1.5 \mathrm{~m}-3 \mathrm{~m}$ and the width of the river varies between $9 \mathrm{~m}-18 \mathrm{~m}$. The banks of the Mookervart river left side directly bordered to the residential population, regional industry, and factories are less structured, while the right side of the Mookervart river is Daan Mogot Road.

Data and Materials Equipment such as: (i) Jakarta Map administration (Source: Coordinating Agency for Land Survey and Agroclimate (Bakosurtanal)), (ii) Data rainfall of Jakarta in 2002-2014 (Source: Meteorological and Geophysics Agency (BMG) Pondok Betung), (iii) Hydrology Map of Group Land and Land Cover (source: Map watersheds that flow into Jakarta, 2014) and (iv)Flow and water level data of the Mookervart River. (Source: Office of Public Works Jakarta)

The scope of the study includes : the forecast value of the catch water runoff generated around Mookervart River in Jakarta based method.The basic model of catchment-scale hydrology is the conservation of mass equation [1]. 


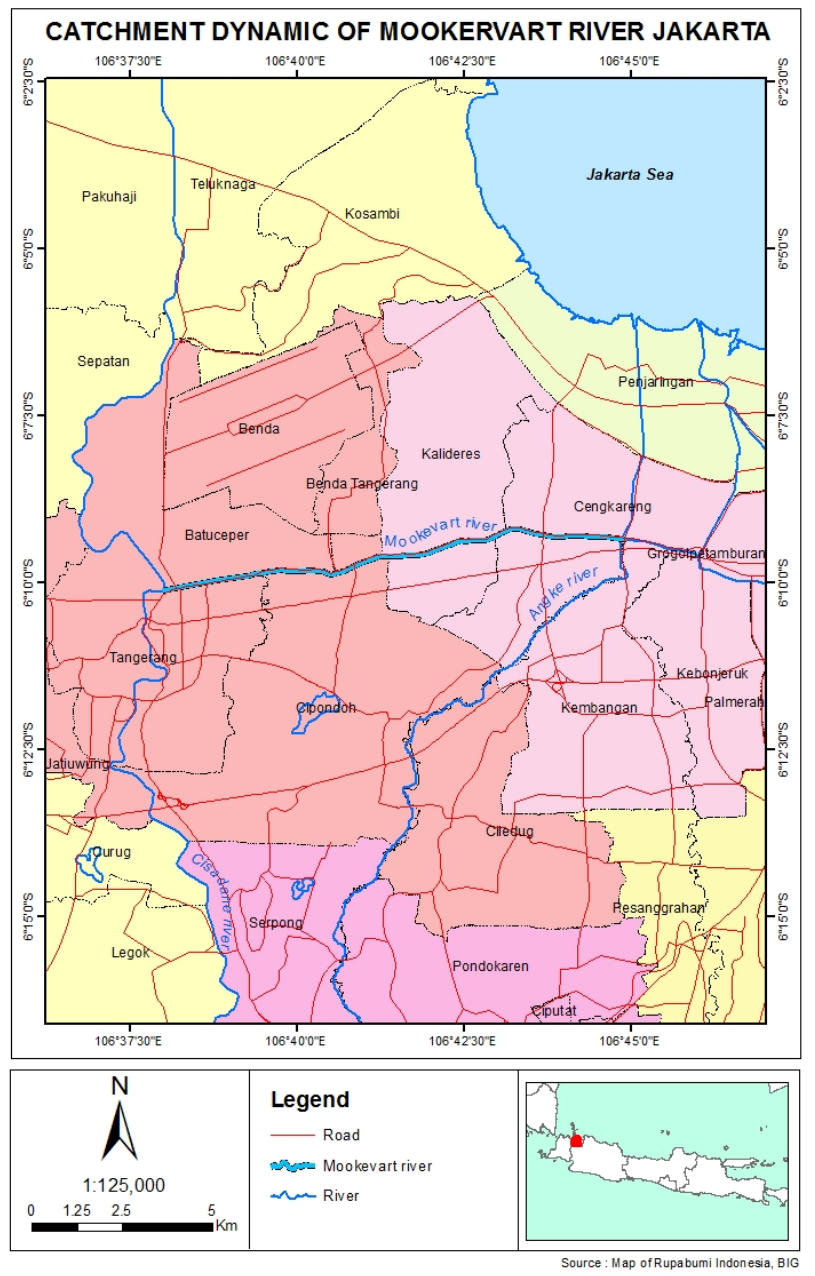

Fig. 1. The Mookervart catchment area.

\subsection{Reaserch Methods}

The study consisted of three phases. The first stage is a map overlay watershed delineation Mookervart with administrative boundaries Jakarta. The second stage is to make a map of the rainfall area of Jakarta and surrounding areas, the process of overlaying maps and rainfall, calculation of watershed surface (Q) resulting from each use of land in Jakarta and overlay maps with the maximum discharge of Jakarta and final stage using Cachment Model based on simple Nonlinier Dynamical System. 


\subsection{Methods of Analysis}

\subsubsection{Remote Sensing Technique}

The Development and evolution of the lake will be studied by using satellite images such as Landsat TM. The remote sensing technique is used to acquire the lake area reduction and water quality deterioration information of urban lakes. The appropriate classification rule sand retrieval model were selected to obtain the important information regarding lake dynamics, such as the lake boundaries, land use classification, lake temperature and chlorophyll content based on the multi-source remote sensing images (MODIS, SPOT etc). The phenomena such as the abnormal change of the urban lake and track the development trend will be obtained.

\subsubsection{Observation}

In this research we conduct 1 year observation with sampling interval one weak for the parameters organic carbon, grab sampling, water quality, time series of temperature, salinity, $\mathrm{pH}$ etc.

\subsubsection{Environmental Modeling}

We use general mass balance equation to quantifying carbon budget in the lake and surrounding area. The model will be used to studies biological and/or chemical processes normally associated with water quality such as nutrient cycling studies; algal succession studies; food-web investigations; pathogen dynamics investigations; suspended solids studies; particulate carbon and toxic metal studies. Based on this simulation and comparison with observation data we can quantify carbon budget in Urban Lake.

\subsection{Catchment Model based on Simple Nonlinear Dynamical System}

The basic model of catchment-scale hydrology is the conservation of mass equation [1],

$$
\frac{d S}{d t}=P-E-Q
$$

where $S$ is the volume fo water storage in the catchment area (mm depth), $P$ is the rate of praticipation, $E$ is the evapotranspiration and $Q$ is the discharge. All the function $S, P, E$ and $Q$ are function of times. In this paper we use a conceptual model. This model has two criterias: first, the structure of the model is specified prior to any modelling undertaken and the second not all parameters have a direct physical interpretation [4]. Further, we assume that the complex behaviour of a catchment area can be described by using a coupled nonlinear differential equation. This model has been used to predict the behavior of climate system such as El Nino and Sothern Oscillation. In the hydrological science, several scientist have discovered that a low dimensional model such as rainfall $(R)$ and $\operatorname{runoff}(S)$ can be used to predict the behavior of hydrological processes. The method is called chaotic dynamics [5]. This system is sensitive to initial condition and there is no random effect involved [6]. 
In this paper we proposed dynamical model of run-off and rainfall as follow,

$$
\begin{gathered}
\frac{d R}{d t}=\mu R-v R S \\
\frac{d S}{d t}=\alpha S-\gamma S^{3}+\lambda R S
\end{gathered}
$$

The system in sensitive to initial condition where this mean that the long range prediction is imposible. There are three properties of the system: steady state or stable, limit cycle and chaotic behavior.

\section{Result and Discussion}

Three phase have been used for making GIS Map in this study. The first stage is a map overlay between watershed delineation Mookervart Rivermap and administrative boundaries of Jakarta map. The second stage is mapping construction of the rainfall area of Jakarta and surrounding areas, and thencalculation of surface discharge (Q) which result from each land use in Jakarta. The final stage is overlaying map of Jakarta district with maximum discharge of Jakarta.

Data Processing using Mathlab (The MathWorks, Inc. 3 Apple Hill Drive Natick, MA 01760-2098). Such as: importing and exporting data, plotting data, missing data, inconsistent data, filter data, smooth data with convolution, detrending data and descriptif statistic.The rainfall data form 2002 to 2014 is depicted Fig.2.

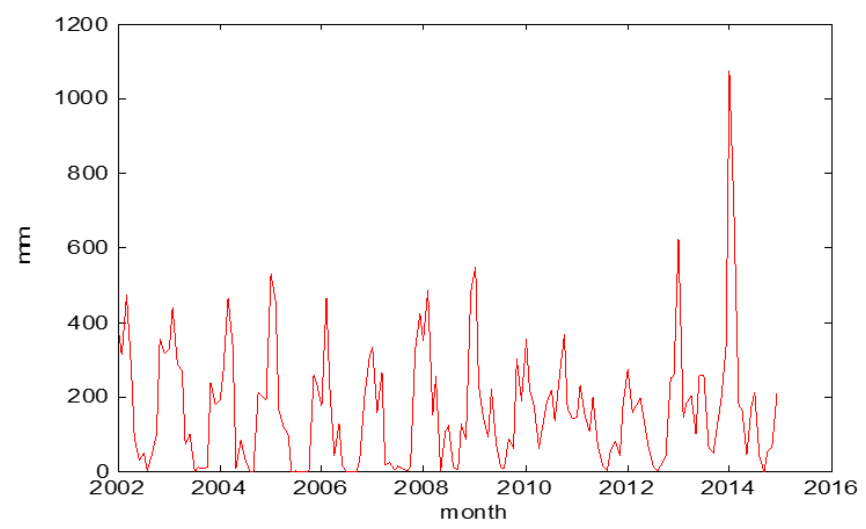

Fig. 2. The rainfall data from 2002 to 2014 .

From Fig. 2 we can see that the average of rainfall was taken as long12 year showed that rainfall in Mookervart River under $500 \mathrm{~mm} / \mathrm{month}$ which can we say "wet month". Mookervart river system was caused by 2 season: wet and dry month. The dry month starting from month of May up to October.From November up to April is wet month (Fig.2).From Fig. 2 we can see that in 2010 the wet month more longes than other year. In 2014 the wet season more than other year is caused by La Nina effect.

Now, we describe the nonlinear dynamics of Mookervart catchment area. The simplest model describe by only one variale. Let we describe the Equation (1) or example, the runoff equation with no rainfall can be modeled by the equation as follow,

$$
\frac{d S}{d t}=\alpha S\left(1-S^{2}\right)
$$


This is called evolution equation. The solution of the equation depend on the parameter $\alpha$ is depicted in Fig.3.

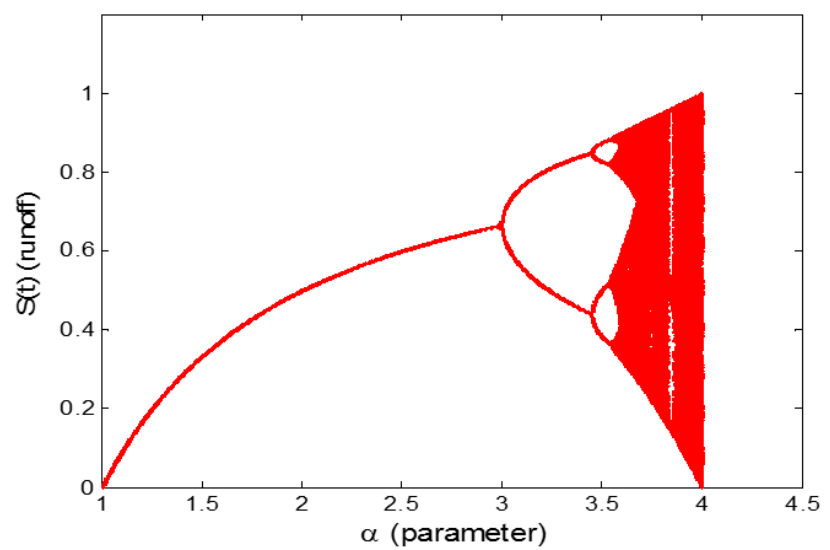

Fig.3. The bifurcation diagram of Equation (4).

\section{The solution of a differential equation.}

The solution of a differential equation has a unique solution if it well behavior (one-one mapping). The figure show that at the $\alpha=3$ the equation has two solution, this is mean that the solution is not unique. When the value of parameter increase then there are many kind of solution. This condition is called bifurcation. This is a restriction of a parameter value in our system. The solution of Equation (4) is depicted in Fig. 4.

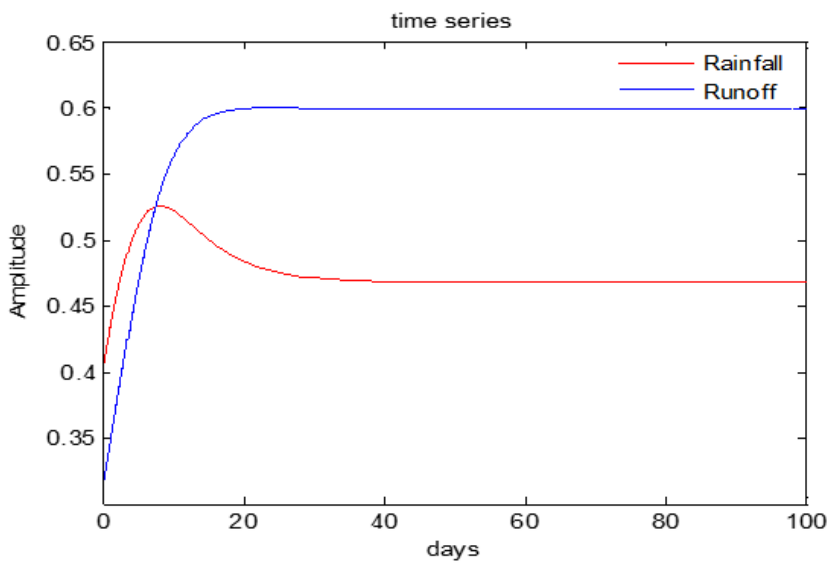

Fig.4. Solution of Equation 4 with parameter value are $\mu=0.14 ; \nu=0.5 ; \alpha=0.12 ; \gamma=0.4$;

$$
\lambda=0.05 \text {; }
$$

From Fig. 4, we can see that rainfall on 8th days shown that incrising and decresing from 15th day and then stabilize from 20th day to 100th day. Run off on the 18th days shown that incrising optimally and stabilize from 18th day to 100th day. The part or $50 \%$ of rainfall can be absorp to the land and others can be change to the run off form. The application this model into the observation data of Mookervart catchment area is still ini progress. 


\section{Conclusions}

The proposal a nonlinear dynamical system for Mookevart catchment area is breafly given. We proposed a nonlinear dynamical system describing Mookervart catchment area. The bifurcation analysis is given and numerical solution of equation is also described. The simulation show that the runoff profile is depend on the rainfall input.

This research founded by the grant of LPM of Syarif Hidayatullah State Islamic University 2016.

\section{References}

[1] W. Brutsaert, Hydrology, An Introduction, Cambridge University Press, (2005)

[2] A. Rinaldo, A. Marani and R. Rigon, Geomorphological Dispersion, Water. Resour, Res. 27, 513-523, (1991)

[3] J.W. Kircher, Catchments as Simple Dynamical Systems: Catchment Characterization, Rainfall-Runoff Modelingand Doing Hydrology Backward, Water Resources research, 45, (2009)

[4] I.G. Pechilivandis, B.M. Jackson, N.R. Mcintyre and H.S. Wheather, Catchment Scale Hydrological Modeling: AReview of Model Types, Calibration Approachs and Uncertainty Analysis Methods in the Context of Recent Development in Technology and Application, Global NEST J., 13(3), 193-124, (2011)

[5] D. Koutsoyiannis, On the Quest for Chaotic Attractors in Hydrological Processes, Hydrological sciences, J. des Sceinces Hydrologiques, 51 (6), 1065-1092,(2006).

[6] S. Wiggin, Introduction to Applied Nonlinear Dynamical System and Chaos, Springer Verlag, Berlin, 820, (2003) 